\title{
Antioxidative activity of gold and platinum nanoparticles assessed through electron spin resonance
}

\author{
Angela Kinoshita $^{1} \oplus{\text { Iara } \operatorname{Lima}^{2} \oplus, \text { Éder José Guidelli }^{2} \oplus \text {, Oswaldo Baffa Filho }}^{2+}{ }^{\oplus}$ \\ 1. Universidade do Oeste Paulista, Pró-Reitoria de Pesquisa e Pós- Graduação, Presidente Prudente, Brazil. \\ 2. Universidade de São Paulo, Faculdade de Filosofia, Ciências e Letras de Ribeirão Preto, Ribeirão Preto, Brazil.
}

+Corresponding author: Oswaldo Baffa Filho, Phone: +55 16 3315-3642, Email address: baffa@usp.br

\section{ARTICLE INFO}

Article history:

Received: September 13, 2020

Accepted: November 17, 2020

Published: April xx, 2021

\section{Keywords}

1. gold nanoparticle

2. platinum nanoparticle

3. antioxidative

4. DPPH

\begin{abstract}
Gold nanoparticle (AuNP) is a well-known biocompatible structure with several biomedical applications for labeling, heating, and sensing, besides delivery of drugs to cells. Similarly, platinum nanoparticles (PtNPs) have important applications in medicine. Traditional applications of these nanoparticles in medicine/biomedicine depend on their physical-chemical properties. In this work, a preliminary study of the antioxidative properties of AuNP and PtNP was performed using electron spin resonance (ESR) spectroscopy. Antioxidant activity against DPPH (1,1-diphenyl-2-picrylhydrazyl) radical was found for both nanoparticles, but the PtNP was more reactive than the AuNP to reduce the DPPH ESR signal. The decay time for the signal intensity was $T=3.1 \pm 0.1 \mathrm{~min}^{-1}$ for AuNP and $T=1.80$ $\pm 0.07 \mathrm{~min}^{-1}$ for PtNP.
\end{abstract}

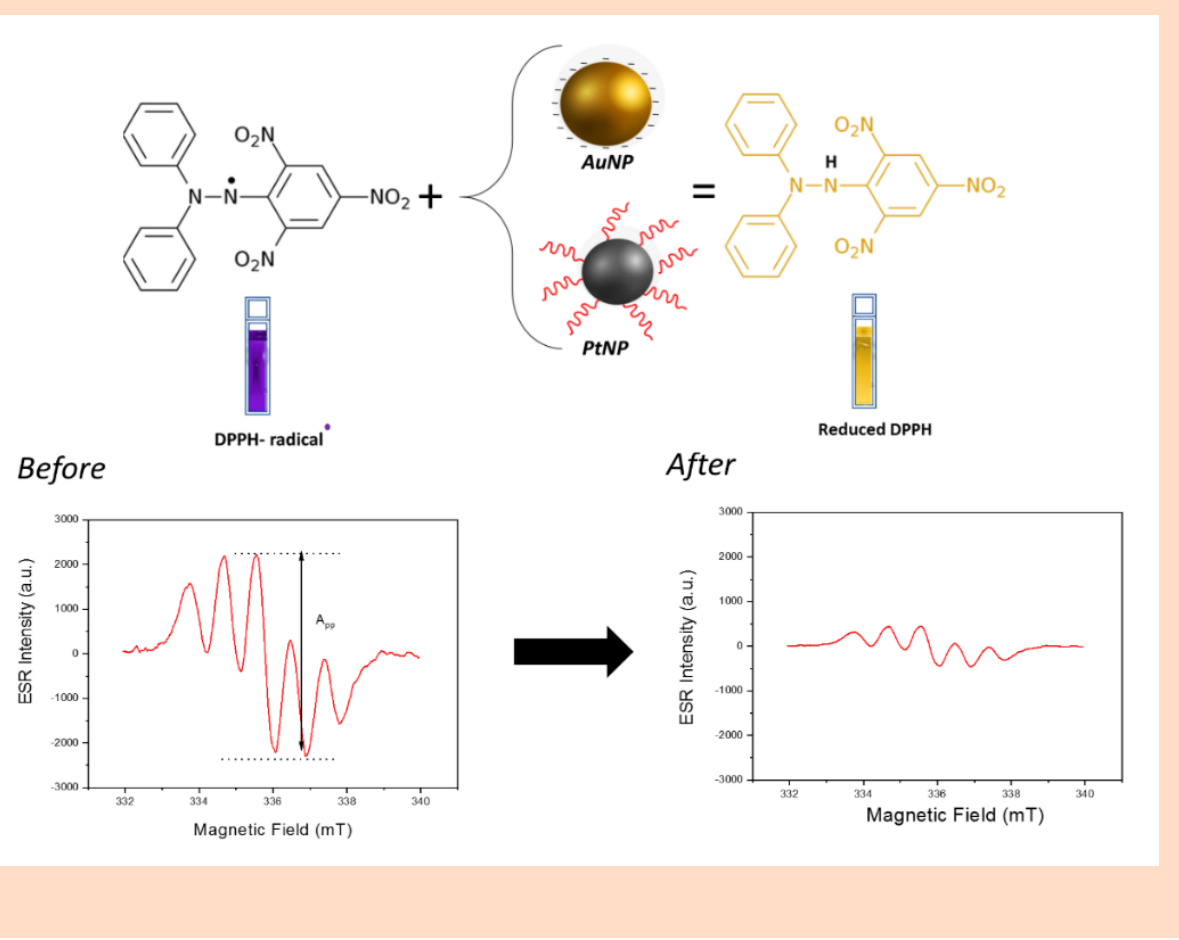




\section{Introduction}

Metal nanoparticles have been known for a long time and have always called the attention due to their optical features. The photophysical properties of the particles or of nearby molecules (such as absorption, scattering, fluorescence, and Raman scattering) are enhanced due to the interaction of light with the free electrons on the metal nanoparticle surface. The electromagnetic field of light causes a coherent collective oscillation of the conduction band electrons giving rise to the surface plasmon resonance ${ }^{1}$.

These nanoparticles can be synthesized by several methods. For instance, the most traditional protocol for gold nanoparticles (AuNPs) synthesis was proposed by Turkevich, consisting of the reduction of tetrachloroauric acid $\left(\mathrm{HAuCl}_{4}\right)$ with sodium citrate at 90-100 ${ }^{\circ} \mathrm{C}$. Sodium citrate acts both as reducing and stabilizing agent, but other agents have been used, such as borohydrides, aminoboranes, hydrazine, formaldehyde, etc. ${ }^{2}$. Deraedt et al. ${ }^{3}$ observed that the ratio between salt and Borohydride during reaction alters the particle dimensions and, consequently, its optical and catalytic properties. For each proportion, a different color of colloidal suspension was obtained; the ratio $1 \mathrm{Au}: 10 \mathrm{NaBH}_{4}$ produced AuNPs with size of about $3 \mathrm{~nm}$ and high stability.

Polymers can stabilize AuNPs; they are versatile and enable to control the size, solubility, amphiphilicity, compatibility among other characteristics with the use of specific ones ${ }^{2}$. Chitosan is a commonly used polymer employed to produce AuNP, it is a natural product and can be used as stabilizing and reducing agent, making a green synthesis of nanoparticles possible. Offering good biocompatibility and other features enabling applications in biomedicine and several others areas ${ }^{4}$. Similarly, alanine is an amino acid that can be used to stabilize AuNP. One of the important applications of alanine is as an ionizing radiation sensor and dosimeter $^{5}$. When associated with AuNPs, this dosimeter becomes more sensitive, allowing the detection of smaller doses of radiation, which expands the field of applications in ionizing radiation dosimetry ${ }^{6}$.

The fact that polymers and other molecules can bind to AuNP greatly expands its application. In the field of biological applications, Sperling ${ }^{7}$ explains in details several uses in which highlights labeling, delivering, heating, and sensing. For labeling, usually a molecule with a functional group that associates with specific sites in cells is linked to the nanoparticle. This bond can be directly on the surface of the nanoparticle or by partial replacement of the stabilizer. Thus, this molecule will direct AuNP to regions of interest in the material, concentrating AuNP, providing contrast at these specific sites. Subsequently, the visualization can be optical by the interaction of AuNP with light or by transmission electron microscopy (TEM), since $\mathrm{Au}$ is a metal with a high atomic weight, causing high contrast. It is also possible to obtain contrasted images with $\mathrm{X}$ rays. Gold nanoparticles are conjugated with specific antibodies or ligands, the solution is applied (in animals) and it is specifically uptake by the organ of interest. Thus, in X-ray tomography it is possible to visualize the region of interest with high contrast and resolution by the presence of AuNP.

Nie et $a .^{8}$ functionalized AuNP with Trolox, an antioxidant substance. Their results showed an improvement of chemical reactivity, enhancing the antioxidant activity, suggesting that the assembling of organic molecules on AuNP can endow these molecules with reactivity higher than the sum of the monomers. Other studies such as Rajan et al. ${ }^{9}$ used phytochemicals present in Areca catechu to synthesize AuNP and obtained a compound with antioxidant, antibacterial, and anticancer potential.

Gold nanoparticles are also used as delivery vehicles for substances. These are attached to the nanoparticle surface, that are introduced into the cells. Inside the cells, the substances detach themselves. Similarly, in hyperthermia, nanoparticles are introduced in cells. They can be targeted, for example, to cancer cells through ligands that are specific to the receptors of these cells. Through absorption of light, AuNPs are heated, raising the temperature of the neighborhood, which can lead to the death of cancer cells. The heating triggered by light also allows AuNP to control the delivery of substances. In this case, AuNPs are associated with polymers that form small capsules, containing the substance. Thus, through interaction with the light, this capsule heats up, breaks, and then the substance is released.

The use of AuNP as sensors in the colorimetric method is based on altering the wavelength peak of plasmonic absorption in the presence of the substance to be detected. Gold nanoparticles can be functionalized by molecules that specifically bind to a particular substance. In this case, the substance leads to the agglomeration of AuNP, shifting the plasmonic peak and consequently changing its color, from red to white or blue. In other techniques, fluorescent substances are used. When in close contact with AuNP, the fluorescence is annihilated and, when the fluorophores are far away, with the presence/absence 
of analyte, the light emitted is detected and related to the concentration.

In the last decades, platinum nanoparticles (PtNPs) have also been employed extensively in the field of chemistry and medicine, as glucose and gas sensors ${ }^{10}$, catalysts in fuel cells ${ }^{11,12}$ and in cancer treatment ${ }^{13}$. Also, PtNPs are a promising alternative as an agent that enhance the dose of ionizing radiation in cancer treatment ${ }^{13}$. In radiotherapy, the insertion of PtNPs could increase the probability of interaction with ionizing radiation due to its high atomic number and consequently increasing the local dose and the radiosensitization of the tumor tissue ${ }^{14-16}$.

The anticancer drugs known as cisplatin and oxaliplatin have been employed in chemotherapy for quite some time with good results ${ }^{17,18}$. Platinum nanoparticles present low toxicity in human cells and are therefore used commercially in chemotherapy ${ }^{19}$. Studies about the toxicity of 5-8 nm PtNPs in human cells concluded that the toxicity can be passivated by coating their surfaces with polyvinyl alcohol (PVA). It is also shown, in cell culture, that the toxicity depends on the concentration of PtNPs (higher concentration, higher toxicity); and are independent of time and cell lineages. In addition, the functionalization of the PtNPs surface can reduce the damage in renal tissues caused by cisplatin; as demonstrated in the literature, the combination of an antihypertensive and antioxidant carvedilol $(\mathrm{CV})$ with chemotherapy drug was able to reduce kidney damage without interfering in the biodistribution or genotoxicity of cisplatin ${ }^{20}$.

The properties of PtNPs depend strongly on the size, shape and structure that can be controlled in the synthesis process. The most common routes for synthesis of PtNPs in colloidal suspension is through chemical reduction ${ }^{21}$, microemulsions ${ }^{22}$, green synthesis ${ }^{23}$ and gamma irradiation ${ }^{24}$ by the reduction of precursors, such as $\mathrm{Pt}^{4+}$ or $\mathrm{Pt}^{2+}$ ions in the presence of coating agent. In order to control size and morphology, polyacrylate and polyvinylpyrrolidone were used ${ }^{25}$; however, the use of $\mathrm{NaBH}_{4}$ is related as a faster reducing agent employed for the synthesis and control of $\operatorname{size}^{26}$.

Moreover, PtNPs have been shown to a have potential antioxidant activity ${ }^{27}$. Platinum nanoparticles reduced the effect of reactive oxygen species $(\mathrm{ROS})^{28,29}$. Due to this strong antioxidant activity, PtNPs have been effectively used in the pharmaceutical area, as antiaging formulations in the cosmetic sector. This antioxidant potential was used to prevent the effects of ROS lung diseases attributed to oxidative stress $^{30}$.
Electron spin resonance (ESR) is a powerful spectroscopic technique to detect and quantify free radicals in different mediums. In solid state free radicals created by ionizing radiation can be used for dosimetry $^{5,31-33}$ and archeological dating ${ }^{34,35}$ for instance. In solutions, the nature of radicals created by different processes can also be studied ${ }^{36}$. The antioxidant effect of different substances can also be studied in a straightforward way ${ }^{37,38}$. Because it is not a colorimetric method, it can be useful for substances that are not colorless. Thus, antioxidant extracts of plants were studied allowing a fast selection of those with potential for pharmaceutical use ${ }^{39}$. In this work, AuNP and PtNP were prepared by reducing gold salt $\mathrm{HAuCl}_{4}$ and platinum salt $\left(\mathrm{H}_{2} \mathrm{PtCl}_{6} .6 \mathrm{H}_{2} \mathrm{O}\right)$ by sodium borohydride $\mathrm{NaBH}_{4}$. The antioxidant activity of AuNP was studied by ESR, through the observation of DPPH (1,1-diphenyl-2-picrylhydrazyl) radical annihilation. These properties are important in the biomedical area, since free radicals are associated with several pathologies, including delay of the healing processes.

\section{Experimental}

\subsection{Synthesis AuNP}

All chemicals and solvents used for the syntheses were of commercially available reagent grade and applied without further purification.

Gold nanoparticles were obtained by chemical reduction of the gold salt, $\mathrm{HAuCl}_{4}\left(4 \mathrm{mmol} \mathrm{L}^{-1}\right)$ by sodium borohydride $\mathrm{NaBH}_{4}\left(8 \mathrm{mmol} \mathrm{L} \mathrm{L}^{-1}\right)$, under vigorous stirring. The system is kept under agitation of $400 \mathrm{rpm}$, for $12 \mathrm{~h}$ in order to guarantee the total reduction of gold. The formation of AuNP can be confirmed by changing the color of the solution from yellow to red, indicating the formation of colloidal gold and the presence of the plasmonic peak in the UVVis spectrum around $515 \mathrm{~nm}^{6}$.

\subsection{Synthesis PtNP}

Platinum nanoparticles were synthetized by the chemical reduction of the platinum salt $\mathrm{H}_{2} \mathrm{PtCl}_{6} \cdot 6 \mathrm{H}_{2} \mathrm{O}$ $\left(2 \mathrm{mmol} \mathrm{L} \mathrm{L}^{-1}\right)$ in the presence of sodium borohydride $\mathrm{NaBH}_{4}\left(4 \mathrm{mmol} \mathrm{L}^{-1}\right)$ using polyvinyl alcohol (PVA) as capping agent. The system was kept under vigorous stirring for $18 \mathrm{~h}$ for all reduction. The color of the system became immediately bright yellow, indicating the formation of a colloidal dispersion. The characteristic absorption peak of the PtNPs in the UVVis spectrum is $260 \mathrm{~nm}^{40}$. 


\subsection{Anti-oxidative activity against DPPH}

The anti-free radical activity of the synthesized AuNP and PtNP was studied by ESR spectroscopy. For these tests, $200 \mu \mathrm{L}$ of the nanoparticle solution and $200 \mu \mathrm{L}$ of the ethanol solution $200 \mu \mathrm{mol} \mathrm{L} \mathrm{L}^{-1} \mathrm{DPPH}$ free radical (1,1-diphenyl-2-picrylhydrazyl radical) were used. After the reaction, the resulting solution was transferred to a glass capillary tube (hematocrit tube), inserted in a quartz tube, and placed in the ESR resonant cavity to take the spectra.

The ESR spectra were acquired sequentially every 1 min on the ESR Jeol FA-200-Band X spectrometer, at room temperature, to study the kinetics of the reaction between the nanoparticles and the DPPH radical.

The parameters of the spectrometer for spectra acquisition were: central field $345 \mathrm{mT}$, scan $10 \mathrm{mT}$, scan time $1 \mathrm{~min}$, modulation amplitude $0.1 \mathrm{mT}$, power $1 \mathrm{~mW}$, modulation frequency $100 \mathrm{kHz}$ and microwave frequency $9.5 \mathrm{GHz}$.

\section{Results and Discussion}

\subsection{Anti-oxidative activity against DPPH}

In this work, ESR and DPPH were employed to determine the antioxidant activity of AuNP. The DPPH is widely used as a radical molecule to evaluate the antioxidative properties of various compounds, using ESR. The DPPH radical is able to accept an electron or hydrogen atom (proton) to become a stable diamagnetic molecule ${ }^{41}$. Nie et al. ${ }^{8}$ studied AuNP functionalized with antioxidant molecules through ESR DPPH radical scavenging tests. They observed an enhancement of antioxidative ability after functionalization. Esumi et $\mathrm{al}^{4}{ }^{4}$ showed the antioxidative ability of AuNP prepared in the presence of chitosan. The authors used the spin trapping method with DMPO (5,5-dimethyl-1-pyrroline-N-oxide) to monitor the elimination of hydroxyl radicals generated by Fenton reaction. They observed a decrease of ESR DMPO-OH signal when increasing the concentration of gold-chitosan.

In this sense, by monitoring the signal intensity of the ESR spectrum, the radical scavenging activity of substances can be studied. The antioxidant activity of substances can also be assessed with DPPH and the optical method, since the DPPH solution has its color changed from violet to yellowish as the reaction occurs. So, the natural coloring of the substances can interfere in the procedure, which does not occur when using the ESR, since the radical is detected directly without color interference. Figure 1a shows DPPH ESR spectrum reacted with methanol and the $A_{p p}$, Amplitude considered to monitor the reaction. After reaction with AuNP, the amplitude $A_{p p}$ decays, showing the free radical scavenging capacity (Fig. 1b).

Experimental data points were adjusted with a single exponential curve decay (Eq. 1):

$I=I_{0} \cdot e^{-t / T}+c$

Resulting in $I_{0}=3791 \pm 65, T=3.1 \pm 0.1 \mathrm{~min}^{-1}, \mathrm{c}=$ $552 \pm 14$, and adjusted R-square 0.993 for AuNP; and $I_{0}=3701 \pm 51, T=1.80 \pm 0.07 \mathrm{~min}^{-1}, \mathrm{c}=604 \pm 10$, and R-square 0.995 for PtNP, revealing superior antioxidative properties of PtNPs compared to AuNPs.
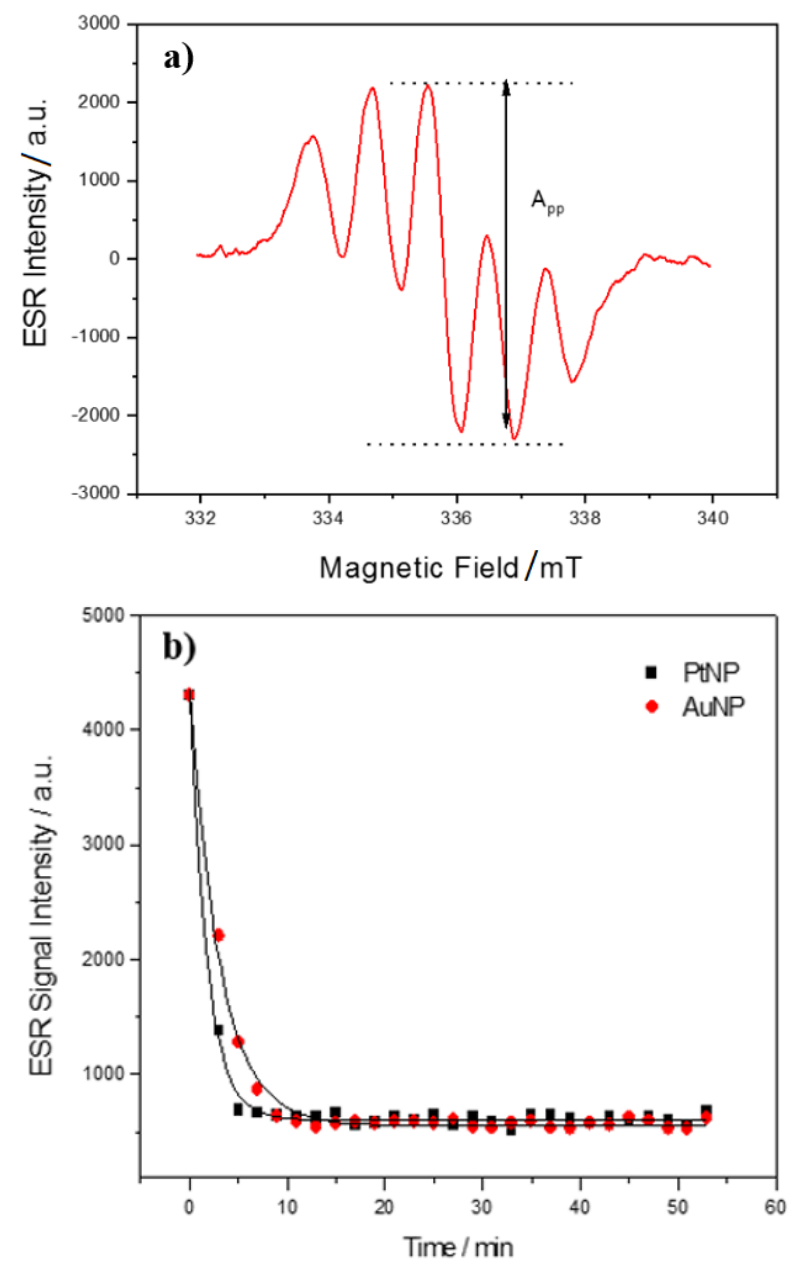

Figure 1. (a) Electron spin resonance spectrum of DPPH $200 \mu \mathrm{mol} \mathrm{L} \mathrm{L}^{-1}$ and (b) decay of DPPH ESR signal amplitude after reaction with AuNP (circle) and with PtNP (square). 


\section{Conclusions}

Gold and platinum nanoparticles can be easily produced by reducing the salt with sodium borohydride. Both nanoparticles presented antioxidative properties, but the results suggest that superior antioxidative properties of PtNPs. These results can be of great importance for biological environments, evidencing that their antioxidative effect should be considered in biomedical applications.

\section{Acknowledgments}

This research was partially funded by the Brazilian agencies Fundação de Amparo à Pesquisa do Estado de São Paulo (FAPESP CEPID-NEUROMAT 13/076990), Coordenação de Aperfeiçoamento de Pessoal de Nível Superior (CAPES, finance code 001) and Conselho Nacional de Desenvolvimento Científico e Tecnológico (CNPq grant 304107/2019-0). The technical support of Eldereis de Paula, Lourenço Rocha and Carlos R. da Silva is also appreciated.

\section{References}

[1] Huang, X., Jain, P. K., El-Sayed, I. H., El-Sayed, M. A., Gold nanoparticles: interesting optical properties and recent applications in cancer diagnostics and therapy, Nanomedicine $2 \quad$ (5) (2007) 681-693. https://doi.org/10.2217/17435889.2.5.681.

[2] Zhao, P., Li, N., Astruc, D., State of the art in gold nanoparticle synthesis, Coordination Chemistry Reviews 257 (3-4) (2013)

https://doi.org/10.1016/j.ccr.2012.09.002.

[3] Deraedt, C. Salmon, L., Gatard, S., Ciganda, R., Hernandez, R., Ruiz, J., Astruc, D., Sodium borohydride stabilizes very active gold nanoparticle catalysts, Chemical

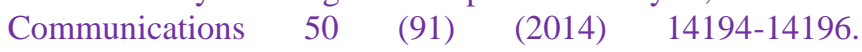
https://doi.org/10.1039/C4CC05946H.

[4] Esumi, K., Takei, N., Yoshimura, T., Antioxidantpotentiality of gold-chitosan nanocomposites, Colloids and Surfaces B: Biointerfaces 32 (2) (2003) 117-123. https://doi.org/10.1016/S0927-7765(03)00151-6.

[5] Baffa, O., Kinoshita, A., Clinical applications of alanine/electron spin resonance dosimetry, Radiation and Environmental Biophysics 53 (2014) 233-240. https://doi.org/10.1007/s00411-013-0509-2.

[6] Guidelli, E. J., Ramos, A. P., Zaniquelli, M. E. D., Nicolucci, P., Baffa, O., Synthesis and Characterization of Gold/Alanine Nanocomposites with Potential Properties for Medical Application as Radiation Sensors, Applied
Materials \& Interfaces 4 (11) (2012) 5844-5851. https://doi.org/10.1021/am3014899.

[7] Sperling, R. A., Gil, P. R., Zangh, F., Zanella, M., Parak, W. J., Biological applications of gold nanoparticles, Chemical Society Reviews 37 (9) (2008) 1896-1908. https://doi.org/10.1039/b712170a.

[8] Nie, Z., Liu, K. J., Chong, C.-J., Wang, L.-F., Yang, Y., Tian, Q., Liu, Y., Enhanced radical scavenging activity by antioxidant-functionalized gold nanoparticles: A novel inspiration for development of new artificial antioxidants, Free Radical Biology and Medicine 43 (9) (2007) 12431254. https://doi.org/10.1016/j.freeradbiomed.2007.06.011.

[9] Rajan, A., Vilas, V., Philip, D., Studies on catalytic, antioxidant, antibacterial and anticancer activities of biogenic gold nanoparticles, Journal of Molecular Liquids 212 (2015) 331-339. https://doi.org/10.1016/j.molliq.2015.09.013.

[10] Kang, W. P., Kim, C. K., Novel platinum-tin oxide-silicon nitride-silicon dioxide-silicon gas sensing component for oxygen and carbon monoxide gases at low temperature, Applied Physics Letters 63 (1993) 421-423. https://doi.org/10.1063/1.110012.

[11] Xie, J., Wang, S., Aryasomayajula, L., Varadan, V. K., Platinum decorated carbon nanotubes for highly sensitive amperometric glucose sensing, Nanotechnology 18 (6) (2007) 065503. https://doi.org/10.1088/0957$4484 / 18 / 6 / 065503$

[12] Chen, A., Holt-Hindle, P., Platinum-Based Nanostructured Materials: Synthesis, Properties, and Applications, Chemical Reviews 110 (6) (2010) 3767-3804. https://doi.org/10.1021/cr9003902.

[13] Porcel, E., Liehn. S., Remita, H., Usami, N., Kibayashi, K., Furusawa, Y., Le Sech, C., Lacombe, S., Platinum nanoparticles: a promising material for future cancer

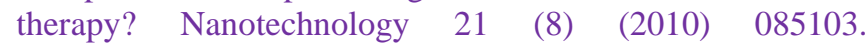
https://doi.org/10.1088/0957-4484/21/8/085103.

[14] Butterworth, K. T., Wyer, J. A., Brennan-Fournet, M., Shah, M. B., Currel, E. J., Hirst, D. G., Variation of Strand Break Yield for Plasmid DNA Irradiated with High-Z Metal Nanoparticles, Radiation Research 170 (3) (2008) 381-387. https://doi.org/10.1667/RR1320.1.

[15] Herold, D. M., Das, C. C., Iyer, R. V., Chapman, J. D., Gold microspheres: a selective technique for producing biologically effective dose enhancement, International Journal of Radiation Biology 76 (10) (2000) 1357-1364. https://doi.org/10.1080/09553000050151637.

[16] Jain, S., Coulter, J. A., Hounsell, A. R., Butterworth, K. T., McMahon, S. J., Hyland, W. B., Hons, B. S., Muir, M. F., Dickson, G. R., Prise, K. M., Currell, F. J., O’Sullivan, J. 
M., Hirst, D. G., Cell-Specific Radiosensitization by Gold Nanoparticles at Megavoltage Radiation Energies, International Journal of Radiation Oncology Biology Physics 79 (2) (2011) 531-539. https://doi.org/10.1016/j.ijrobp.2010.08.044.

[17] Dhar, S., Daniel, W. L., Giljohann, D. A., Mirkin, C. A., Lippard, S. J., Polyvalent Oligonucleotide Gold Nanoparticle Conjugates as Delivery Vehicles for Platinum(IV) Warheads, Journal of the American Chemical $\begin{array}{lllllll}\text { Society } & 131 & \text { (41) (2009) 14652-14653. }\end{array}$ https://doi.org/10.1021/ja9071282.

[18] Brown, S. D., Nativo, P., Smith, J.-A., Stirling, D., Edwards, P. R., Venugopal, B., Flint, D., J., Plumb, J. A., Graham, D., Wheate, N. J., Gold Nanoparticles for the Improved Anticancer Drug Delivery of the Active Component of Oxaliplatin, Journal of the American Chemical Society $132 \quad$ (13) (2010) 4678-4684. https://doi.org/10.1021/ja908117a.

[19] Boulikas, T., Pantos, A., Bellis, E., Christofis, P., Designing platinum compounds in cancer: structures and mechanisms, Cancer Therapy 5 (2007) 537-583.

[20] Rodrigues, M. A. C., dos Santos, N. A. G., Faria, M. C. da, S., Rodrigues, J. L., Kinoshita, A., Baffa, O., Antunes, L. M. G., Barbosa Junior, F., Gobe, G. C., dos Santos, A. C., Carvedilol protects the kidneys of tumor-bearing mice without impairing the biodistribution or the genotoxicity of cisplatin, Chemico-Biological Interactions 245 (2016) 59-65. https://doi.org/10.1016/j.cbi.2015.12.020.

[21] Li, F., Li, F., Song, J., Song, J., Han, D., Li, N., Green synthesis of highly stable platinum nanoparticles stabilized by amino-terminated ionic liquid and its electrocatalysts for dioxygen reduction and methanol oxidation, Electrochemistry Communications 11 (2) (2009) 351-354. https://doi.org/10.1016/j.elecom.2008.11.042.

[22] Ingelsten, H. H., Bagwe, R., Palmqvist, A., Skoglundh, M., Svanberg, C., Holmberg, K., Shah, D. O., Kinetics of the Formation of Nano-Sized Platinum Particles in Water-in-Oil Microemulsions, Journal of Colloid and Interface Science $241 \quad$ (1) 104-111. https://doi.org/10.1006/jcis.2001.7747.

[23] Coccia, F., Tonucci, L., Bosco, D., Bressan, M., d'Alessandro, N., One-pot synthesis of lignin-stabilised platinum and palladium nanoparticles and their catalytic behaviour in oxidation and reduction reactions, Green $\begin{array}{lllll}\text { Chemistry } & 14 & \text { (4) } & \text { (2012) 1073-1078. }\end{array}$ https://doi.org/10.1039/c2gc16524d.

[24] Gharibshahi, E., Saion, E., Influence of Dose on Particle Size and Optical Properties of Colloidal Platinum Nanoparticles, International Journal of Molecular Sciences $13 \quad$ (11) (2012) 14723-14741. https://doi.org/10.3390/ijms131114723.
[25] Ahmadi, T. S., Wang, Z. L., Green, T. C., Henglein, A., El-Sayed, M. A., Shape-Controlled Synthesis of Colloidal Platinum Nanoparticles, Science 272 (5270) (1996) 19241925. https://doi.org/10.1126/science.272.5270.1924.

[26] Nagao, H., Ichiji, M., Hirasawa, I., Synthesis of Platinum Nanoparticles by Reductive Crystallization Using Polyethyleneimine, Chemical Engineering \& Technology 40 (7) (2017) 1242-1246. https://doi.org/10.1002/ceat.201600656.

[27] Yusof, F., Ismail, N. A. S., Antioxidants effects of Platinum Nanoparticles: A Potential Alternative Treatment to Lung Diseases, Journal of Applied Pharmaceutical $\begin{array}{lllll}\text { Science } & 5 & \text { (7) } & \text { (2015) } & \text { 140-145. }\end{array}$ https://doi.org/10.7324/JAPS.2015.50722.

[28] Asharani, P. V., Lianwu, Y., Gong, Z., Valiyaveettil, S., Comparison of the toxicity of silver, gold and platinum nanoparticles in developing zebrafish embryos,

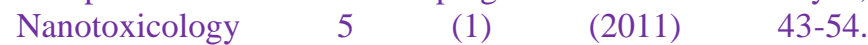
https://doi.org/10.3109/17435390.2010.489207.

[29] Nomura, M., Yoshimura, Y., Kikuiri, T., Hasegawa, T., Taniguchi, Y., Deyama, Y., Koshiro, K.-I., Sano, H., Suzuki, K., Inoue, N., Platinum Nanoparticles Suppress Osteoclastogenesis Through Scavenging of Reactive Oxygen Species Produced in RAW264.7 Cells, Journal of Pharmacological Sciences 117 (4) (2011) 243-252. https://doi.org/10.1254/jphs.11099FP.

[30] Cheng, H., Xi, C., Meng, X., Hao, Y., Yu, Y., Zhao, F., Polyethylene glycol-stabilized platinum nanoparticles: The efficient and recyclable catalysts for selective hydrogenation of o-chloronitrobenzene to o-chloroaniline, Journal of Colloid and Interface Science 336 (2) (2009) 675-678. https://doi.org/10.1016/j.jcis.2009.04.076.

[31] Kinoshita, A., Calcina, C. S. G. Sakamoto-Hojo, E. T., Camparato, M, L., Baffa, O., Evaluation of a High Dose to a Finger from a 60Co Accident, Health Physics 84 (4) (2003) 477-482. https://doi.org/10.1097/00004032-20030400000007 .

[32] Kinoshita, A., Braga, F. J. H. N., Graeff, C. F. O., Baffa, O., ESR dosimetry of ${ }^{89} \mathrm{Sr}-$ and ${ }^{153} \mathrm{Sm}$-in bone, Applied Radiation and Isotopes 54 (2) (2001) 269-274. https://doi.org/10.1016/S0969-8043(00)00159-7.

[33] Kinoshita, A., Baffa, O., Mascarenhas, S., Electron spin resonance (ESR) dose measurement in bone of Hiroshima Abomb victim, PLoS One 13 (2) (2018) e0192444. https://doi.org/10.1371/journal.pone.0192444.

[34] Kinoshita, A., Skinner, A. R., Guidon, N., Ignacio, E., Felice, G. D., Buco, C. de A., Tatumi, S., Yee, M., Figueiredo, A. M. G., Baffa, O., Dating human occupation at Toca do Serrote das Moendas, São Raimundo Nonato, PiauíBrasil by electron spin resonance and optically stimulated 
luminescence, Journal of Human Evolution 77 (2014) 187195. https://doi.org/10.1016/j.jhevol.2014.09.006.

[35] Lopes, R. P., Pereira, J. C., Dillenburg, S. R., Tatumi, S. H., Yee, M, Figueiredo, A. M. G., Kinoshita, A., Baffa, O., Late Pleistocene-Holocene fossils from Mirim Lake, Southern Brazil, and their paleoenvironmental significance: I - Vertebrates, Journal of South American Earth Sciences $100 \quad$ (2020) 102566. https://doi.org/10.1016/j.jsames.2020.102566.

[36] Swartz, H. M., Bolton, J. R., Borg, D. C., Biological Applications of Electron Spin Resonance, WileyInterscience, New York, 1972.

[37] Barbosa, J. H. O., Luna, J. A. G., Kinoshita, A. M. O., Baffa Filho, O., Correlation Between Antioxidant Activity and Coffee Beverage Quality by Electron Spin Resonance Spectroscopic, Ciência e Agrotecnologia 37 (6) (2013) 495501. https://doi.org/10.1590/S1413-70542013000600002.

[38] Barros Silva, R., Santos, N. A. G., Martins, N., M., Ferreira, D. A. S., Barbosa Junior, F., Souza, V. C. O., Baffa, O., Del-Bel, E., Santos, A. C., Caffeic acid phenethyl ester protects against the dopaminergic neuronal loss induced by 6-hydroxydopamine in rats, Neuroscience 233 (2013) 86-94. https://doi.org/10.1016/j.neuroscience.2012.12.041.

[39] Miyahara, M. R. M., Imamura, P. M., de Freitas, J. C., Leonor, S. J., Baffa, O., Kinoshita, A., de Paula-Zurron, A. C. B., Anti-oxidative and anti-ulcerogenic activity of Ipomoea imperati, Revista Brasileira de Farmacognosia 21 (6) (2011) 978-985.

[40] Chen, S., Kimura, K., Synthesis of Thiolate-Stabilized Platinum Nanoparticles in Protolytic Solvents as Isolable Colloids, The Journal of Physical Chemistry B 105 (23) (2001) 5397-5403. https://doi.org/10.1021/jp0037798.

[41] Morales, N. P., Sirijaroonwong, S., Yamanont, P., Phisalaphong, C., Electron Paramagnetic Resonance Study of the Free Radical Scavenging Capacity of Curcumin and Its Demethoxy and Hydrogenated Derivatives, Biological and Pharmaceutical Bulletin 38 (10) (2015) 1478-1483. https://doi.org/10.1248/bpb.b15-00209. 